\title{
Anganwadi centres in society
}

\section{Neethu George*, Mani Prabhu Selvaraju, Swathi Elavarasu, Tharun Ravichandran}

Department of Community Medicine, Dhanalakshmi Srinivasan Medical College, Perambalur, Tamil Nadu, India

Received: 02 May 2021

Accepted: 28 May 2021

\author{
*Correspondence: \\ Dr. Neethu George, \\ E-mail: neethumampuzha@gmail.com
}

Copyright: () the author(s), publisher and licensee Medip Academy. This is an open-access article distributed under the terms of the Creative Commons Attribution Non-Commercial License, which permits unrestricted non-commercial use, distribution, and reproduction in any medium, provided the original work is properly cited.

\begin{abstract}
According to Mahatma Gandhi, "if you educate a man you educate an individual, but if you educate a woman you educate an entire nation." India, in spite of having the world's largest youth population, it has been struggling a lot with the lack of efficient implementation of various policies in the health care system. Since majority of India's population is still residing in the villages, which have a greater say in the overall development of the nation but they are left untouched most of the times either due to improper implementation of the policies or hindrances in the process of development of health care system. Anganwadi's are India's backbone in delivering the healthcare that everyone in country can access to it, by focussing on nutritional supplementation, women's health and so on. This paper is an attempt to shine the light on the impact of the Anganwadi centres in improving the health status of people in the rural areas at grassroot level, focusing especially on women and children's health and the association between the potential contribution of the Anganwadi workers and the child health indicators. Also, current pandemic influences on the centres were quoted.
\end{abstract}

Keywords: Anganwadi centres, Role, Society

\section{INTRODUCTION}

Anganwadi - the word derived from an Indian language "angan", meaning courtyard - the central area in and around the house where all the activities are performed. Also, it's an open space where people meet, converse, do activities as community. Thus, it's a center in community where it is easily accessible to people in small populations for health care, pre-school education, nutrition to children and etc. ${ }^{1}$ This anganwadi system is primarily administered by the anganwadi worker (AWW). She is a health worker selected from the society and is trained for four months in areas such as, health, and nutrition and child-care. She is in charge of an anganwadi centre with a population of 1000. Anganwadi's are India's backbone in delivering the healthcare that everyone in country can access to it, by focussing on nutritional supplementation, women's health and so on. This paper is an attempt to shine the light on the impact of the anganwadi centres in improving the health status of people in the rural areas at grassroot level, focusing especially on women and children's health and the association between the potential contribution of the anganwadi workers and the child health indicators.

\section{METHODOLOGY}

The data were collected from various government and internet sources. The information on the benefits were collected from various articles done in terms of centres. Information were categorised according to the subheadings of the benefits and role done by centres to the society.

\section{ANGANWADI CENTER}

In 2019, there were a total of 13.77 lakh anganwadi centres across the country with 12.8 lakh anganwadi workers and 11.6 lakh anganwadi helpers. Government plans to upgrade 2.5 lakh anganwadi centres in the next five years by the women and child development ministry. They function for four hours a day between 8 am and $12 \mathrm{pm}^{2}$ 
As India is an overpopulated country, the delivery of healthcare services to every people in nook and corner of country is not possible with conventional healthcare facilities and also there is shortage of trained and skilled healthcare professionals. ${ }^{3}$ To address this problem, there comes 'anganwadi centres' - where people can access for healthcare with trained personals, which can identify the issue and refer them to higher centre, provide health education, nutrition and so on. Also, the anganwadi worker is from the same local population, knows their language and easily trusted by them. Thus, they are better than health professionals in reaching out to society. As they live among them, they know the health problems prevailing there and can easily bring it up to the higher authorities.

\section{ROLES AND RESPONSIBILITIES OF AWW}

The roles and responsibilities of the AWW under the integrated and child development services (ICDS) scheme have been stated as follows. ${ }^{4}$ The government's ICDS scheme collaborates with anganwadi centre to implement its objectives: organising supplementary nutrition feeding for the children within the age group of 0-6 years and for expectant and nursing mothers; to organize non-formal pre-school education for the children within the age group of three to five years; sharing all the information relating to births with the panchayat secretary, or gram sabha sevak; to make home visits to educate the parents; to assist the PHC staff in the implementation of health components of the program, i.e., immunisation, health check-up, antenatal and post-natal checks etc.; and to assist in the organization of pulse polio immunization (PPI) drives.

On $2^{\text {nd }}$ of October, 1975, ICDS scheme was launched by the government of India, which focuses on the early childhood care and development and also the pregnant and lactating women. ICDS scheme is world's most unique and largest community-based outreach system for the children and women. The anganwadi worker is the community based voluntary forefront warriors of the ICDS programme. It includes six services: supplementary nutrition, pre-school non-formal education, nutrition and health education, immunization, health checkup, and referral services.

Among these, supplementary nutrition, preschool education and health education are done by anganwadi workers itself without any assistance. For other services they may require assistance from ANM and medical officers. The coming parts will describe few literature done under the services of anganwadi/ICDS.

\section{SUPPLEMENTARY NUTRITION AND HEALTH EDUCATION}

In developing countries, there is inadequacy in the availability of protein, vitamins, minerals, meat and dairy products rich diet to meet the daily requirements and India is no exception, where an unacceptably high undernutrition among pregnant women is considered to be a risk factor for poor birth outcomes.

By the study done by Rai et al, West Bengal, there is a strong association between nutritional supplementation services given to the pregnant and lactating women through the anganwadi centres with the child health indicators such as low birth weight (LBW), very low birth weight (VLBW), extremely low birth weight (ELBW) and neonatal mortality. Odds ratio (OR) with $95 \%$ confidence interval (CI), estimated from multivariate logistic regression models suggest that receipt of nutrition supplements was associated with decreased risk of VLBW, LBW and neonatal mortality (day 0-1) but not ELBW and neonatal deaths (day 2-6 and 7-59). Unorganized and untimely intervention of nutritional supplementation may not be useful in preventing the neonatal mortality deaths. ${ }^{5}$

A study was done by Chudasama et al to calculate supplementary nutrition (SN) activities and its related issues at anganwadi centres. High coverage of reception SN among enrolled was reported in pregnant mothers (88.3\%), lactating mothers $(91.7 \%)$ and adolescents $(86.7 \%)$. Only $25 \%$ AWCs were providing hot cooked food (HCF) to 3 to 6 years children. Less than $50 \%$ of the AWCs were providing ready to eat (RTE) food to 6 months to 3 years children $(48.3 \%)$, pregnant $(46.7 \%)$ and lactating $(46.7 \%)$ mothers, and adolescents $(45.0 \%)$. Total $38.3 \%$ AWCs reported shortage of SN supply, more in rural (41.3\%) compare to urban $(28.6 \%)$. Various problems were reported by anganwadi workers related to SN like lack of storage facility, non-availability of separate kitchen, poor quality of food, irregular supply, inadequate supply, and fuel problem. ${ }^{6}$

Khan et al concluded that in his study, maximum service was utilized by the lactating and pregnant mothers, on the other hand the children of age group between 3-6 years of age utilizes only $50 \%$ which indicates there is no strict monitoring of services. Thus, needs an effective scheme in delivering the services to every corner of the country and all those who are in need. ${ }^{7}$

As per National Family Health Survey (NFHS)-4, 35.85\% female and $28.68 \%$ male children were underweight. Jain et al in their study, they concluded that those who received supplementary nutrition, the prevalence of malnutrition were less. ${ }^{8}$

\section{IMMUNIZATION}

\section{AWW's participation in expanding immunization coverage in rural areas}

Poor immunization coverage in the rural areas has led to increase in the freight of vaccine preventable diseases in the children under the age of 5 years. In spite of various attempts to strengthen the infrastructure and the service delivery, expected vaccine coverage rates could not be 
attained yet. AWW are providing a promising contribution in strengthening the immunization coverage in rural areas. ${ }^{9}$

In a study done by Ghei et al in spite of the immunization being one of the most potential public health interventions in India, latest health survey shows that only $44 \%$ of the children are completely immunized. ${ }^{10}$ A strong disparity has been noted between the urban and rural immunization coverage: urban immunization coverage $-59 \%$, rural immunization coverage - 39\%, and immunization coverage in urban slums $-40 \%$.

In a study conducted by Agarwal et al availability of urban health center within a distance of $2 \mathrm{~km}$ from the urban slum area is directly proportional to twice the likelihood of the urban children under 5 years of age being completely immunized. ${ }^{11}$

With the above studies, we would like to give an inference in that incomplete immunization coverage in rural areas has ultimately resulted in increase in the burden of vaccine preventable diseases and increase in the disabilities of children under 5 years of age. A potential disparity exists in the immunization coverage in the urban and rural areas and also the location of AWC potentially reflects the immunization status of the children under 5 years of age in the urban slums.

\section{Key informants in identifying childhood disabilities}

AWW provide a potential contribution in identifying the children with disabilities especially below 6 years of age. By the study conducted by Y D Singh and their colleagues, out of 1545 children AWW identified 126 children with disabilities and 118 cases were confirmed by pediatricians. ${ }^{12}$

\section{PRE-SCHOOL EDUCATION - A TRUMP CARD TO UPLIFT THE IQ}

In a study conducted by Gupta et al, with the education of mother, sex of the child and PEM grade as the determinants of the study, it was noted that mean development quotient (DQ) and intelligence quotient (IQ) were at higher levels among the children who were exposed to pre-school education in the AWC. Therefore, pre-school education serves as a trump card to improve the early childhood education and development component of the children through the AWC. ${ }^{13}$

A comparative study of preschool education in early childhood education centers in India was done Manhas et al, shows that children who grows in an enriched environment are likely to be self-confident, emotionally stable, well secured and proficient in their language usage. A standard pre-school education intern uplifts the social, cognitive and developmental skills of the children. ${ }^{14}$

With these studies, we conclude that there is a strong proportionality between the IQ and the availability of pre- school education centers and pre-school settings in the anganwadi centers where AWW with higher qualifications demonstrates high quality education and enrich the children with better social, emotional and behavioral gains.

\section{REFERRAL SERVICES AND HEALTH CHECKUP SERVICES}

A cross sectional study conducted by Harikrishna et al, a sample size of 135 was taken in 3 villages, showed that $40.74 \%$ of people utilized the referral services and $82.4 \%$ people utilized health checkup services rendered in the AWC and it was estimated that a significant proportion of the pregnant women utilize the referral services in the AWC. ${ }^{15}$

In a study done by Singh, it shows that the referral services and health checkup services were potentially utilized for treating the childhood disabilities in the children under 5 years of age which were identified by the AWW. ${ }^{12}$

With these studies we conclude that the referral services and health checkup services rendered in the AWC is also used a quality tool in improving the health status of the children under 5 years of age and it also significantly decreases the maternal mortality rate and in preventing the neonatal deaths.

\section{Impact of anganwadi centers on children's caretaker's life}

The three important things which will impact their lives are included below. 16

\section{Direct impact on their wellbeing}

They will have a better mental, physical and emotional health by knowing their children is safe and healthy due to proper nutrition, physical activities and gaining knowledge with preschool education. Thus, they will have a state of rest, comfort and happiness.

\section{Materialistic impact}

With their children in anganwadi centers, they are able to focus on the work and be more productive. Thus, increase the income of the family. With them involving in agricultural work, the productivity of crop will increase which will help them in addition they are helping the countries productivity also. The older siblings of the children will also be benefited without the responsibilities of taking care of their younger sibling and thus they can focus on their own education and improve their knowledge.

With the surplus time they have, they can participate in community meetings and programs and thus involve in the improvement and development of their own society and community. Thus, providing a better future for the upcoming generations. 
With the results of the study conducted by Dwivedi in Amity University, following points were shown.

The mothers felt that they have decreased worry and stress because they feel relaxed that someone in the society who are known to them, trusted by them and have great faith in them are looking after their children. They are so relieved by knowing that their children are playing safely, under supervision, learning poems and with other children - so that they are able to build up a good social life.

Also feel less tired, especially to the women who are going for field works. Learning lessons from AWC in making in nutritious food.

Even though increased family income which is coming from the women's hard work, they don't have economic independence. Thus, there is not much women empowerment.

They will have enough time to go for meetings to share their problems, emotions with other women. They will have a good break from routine.

\section{Impact on anganwadi workers life}

Being an anganwadi workers, they feel that they are motivated to hard work and this is because of the job and their position in community. They feel responsible because they became the trusted by the people of society and thus, they gain a respectful position in the society so that they can handle public issues. In fact, they said that they also learned a lot by working in the AWC like education, hygiene, nutrition. ${ }^{16}$

\section{Anganwadi centres during COVID pandemic}

The pandemic had affected centres also in a bad way. The government had suspended preschool activities in the early 2020. Many states have reported to have a reduction in supplementation of ration and meals to the beneficiaries. So the government have repurposed anganwadi centres in a view to utilize the manpower to tackle various unreached areas of pandemic: capacity building through online sessions; surveillance in a mass setup; health education in terms of preventive and containment measures; tackling stigma and magnifying the positive attitude; support creation and acting as a bridge between various self-help groups, youth wings and established organizations; distribution of take home rations; video/innovation in early childhood education; and ensuring action against domestic violence. $^{17}$

\section{CONCLUSION}

In developing countries like India, utilization of the healthcare services is quiet poor especially among the women and children because of increase in public private partnership in advanced healthcare. On the other hand, in spite of the government efforts and investments in the healthcare system, there is a persistent lag in the expected outcome in the child health indicators. Another potential factor is the divergence of healthcare services from children below 6 years of age and women of lower castes. Though anganwadi centers is designed to address the multidimensional causes of neonatal deaths and maternal mortalities prevalent in rural areas, there is a setback in the betterment of healthcare in rural areas. Hence, it is high time to think over in rectifying the issues emerging in rendering the healthcare services provided under the anganwadi for the better upliftment of the healthcare system from the grass root level.

\section{Recommendations}

The following recommendations were made: formulation of new policies and suggesting changes in existing policies for the upliftment of the healthcare in rural areas; recommending well-structured policies in rendering nutritional supplementation services in order to get a promising outcome in child health indicators; implementation of schemes with extended coverage to provide health care and other services to the adolescent girls in anganwadi centers itself; arranging the wellstructured training programs to the anganwadi workers, since lack of well-trained AWW is also a potential operational difficulty; and conducting more grama sabha sevak to create awareness about the services provided in the anganwadi centers

\section{Funding: No funding sources Conflict of interest: None declared Ethical approval: Not required}

\section{REFERENCES}

1. Kapur R. The Functioning of Anganwadi Centres and Workers. 2018;13.

2. Ministry of Women and Child Development. Available at: https://wcd.nic.in/. Accessed on 24 January 2021.

3. Manhas S, Dogra DA. Awareness among Anganwadi Workers and the Prospect of Child Health and Nutrition: A Study in Integrated Child Development Services (ICDS) Jammu, Jammu and Kashmir, India. Anthropologist. 2012;14:171-5.

4. Sandhyarani M, Rao C. Role and responsibilities of Anganwadi Workers, with special reference to Mysore district. Int $\mathbf{J}$ Sci Environ Technol. 2013;2(6):1277-96.

5. Rai RK, Kumar SS, Prasannanavar DJ, Khandelwal S, Rajkumar H.Rai RK, Kumar SS, Prasannanavar DJ, Khandelwal S RH. Tipping the scale: the role of a national nutritional supplementation programme for pregnant mothers in reducing low birthweight and neonatal mortality in India. Br J Nutr. 2014;1-26.

6. Chudasama R, Kadri A, Joshi N, Bhola C, Zalavadiya D, Vala M. Evaluation of Supplementary Nutrition Activities under Integrated Child Development Services (ICDS) at Anganwadi Centres of Different 
Districts of Gujarat. Online J Heal Allied Sci. 2013;12.

7. Khan AA, Singh AK, Gupta S., Singh J., Khan H, Maheshwari S. Assessment of Supplementary Nutrition Service Utilization at Anganwadi Centres in Rural Area of District Bareilly. Indian J Forensic Comm Med. 2016;3(1):20.

8. Jain I, Oberoi S, Jain A, Balgir R, Sandhu M, Lugani Y. Factors affecting nutritional status of Anganwadi children: A cross-sectional study. J Fam Med Prim Care. 2020;9(9):4613-7.

9. Patel AR, Nowalk MP. Expanding immunization coverage in rural India: A review of evidence for the role of community health workers. Vaccine. 2010;28(3):604-13.

10. Ghei K, Agarwal S, Subramanyam MA, Subramanian SV. Association Between Child Immunization and Availability of Health Infrastructure in Slums in India. Arch Pediatr Adolesc Med. 2010;164(3):243-9.

11. Agarwal S, Bhanot A, Goindi G. Understanding and addressing childhood immunization coverage in urban slums. Indian Pediatr. 2005;42(7):653-63.

12. Mathur GP, Mathur S, Singh YD, Kushwaha KP, Lele SN. Detection and prevention of childhood disability with the help of Anganwadi workers. Indian Pediatr. 1995;32(7):773-7.
13. Gupta S, Raut A. Chapter-05 Early Childhood Development: Maximizing the Human Potential. 2016;51-64.

14. Manhas S, Qadiri F. A comparative study of preschool education in early childhood education centres in India. Contemp Issues Early Child. 2010;11(4):443-7.

15. Harikrishna B, Jothula K, Nagaraj K, Prasad V. Utilisation of Anganwadi services among pregnant women in rural Telangana: A cross sectional study. $\mathrm{J}$ Fam Med Prim Care. 2020;9(7):3343-8.

16. Dwivedi R, Nagda V. Impact of Anganwadi (as Rural Day Care Centre for Children) on Mothers and Elder Siblings. 2013.

17. KPMG. Response to COVI D-19 by the Anganwadi ecosystem in India. 2020; Available at: https://home.kpmg/content/dam/kpmg/in/pdf/2020/0 6/anganwadi-report-2020.pdf? Accessed on 24 January 2021.

Cite this article as: George N, Selvaraju MP, Elavarasu S, Ravichandran T. Anganwadi centres in society. Int J Community Med Public Health 2021;8:3629-33. 